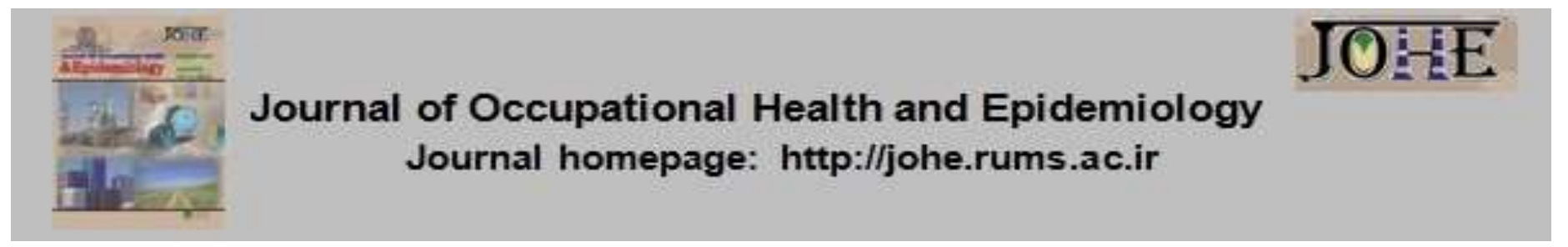

\title{
An Investigation of the Immune Response to Hepatitis B Vaccination in Hemodialysis Patients at Dialysis Centers of Tehran (2016)
}

\author{
Hossein Hatami ${ }^{1}$, Parvaneh Movafagh ${ }^{2}$, Ali Ramezankhani ${ }^{3}$
}

1- Prof. of Infectious and Tropical Diseases and Master of Public Health (MPH), Dept. of Public Health, School of Health and Environmental and Occupational Hazard Control Research Center, Shahid Beheshti University of Medical Sciences, Tehran, Iran.

2- Master of Public Health (MPH), Dept. of Public Health, School of Public Health and Immunity, Shahid Beheshti University of Medical Sciences, Tehran, Iran.

3- Prof. of Health Education \& Health Promotion, School of Public Health, Shahid Beheshti University of Medical Sciences, Tehran, Iran.

Citation: Hatami H, Movafagh P, Ramezankhani A. An Investigation of the Immune
Response to Hepatitis B Vaccination in Hemodialysis Patients at Dialysis Centers of Tehran
(2016). JOHE 2019; 8(4):171-5.

\section{Article Info}

* Corresponding author:

Parvaneh Movafagh,

E-mail:

pmovafagh@yahoo.com

\section{Article history}

Received: Sep 2019

Accepted: Apr 2020

10.29252/johe.8.4.171

Print ISSN: 2251-8096 Online ISSN: 2252-0902

Peer review under responsibility of Journal of Occupational Health and Epidemiology

\begin{abstract}
Background: Hemodialysis (HD) patients are at an increased risk of acquiring the hepatitis $B(\mathrm{HB})$ virus and having lower protective antibody levels as well as shorter durations of seroprotection. This study aims to determine the immune response of HB vaccination in HD patients referring to dialysis centers of the Tehran North Health Network.

Materials and Methods: This descriptive study was conducted among all HD patients who referred to dialysis centers of the Tehran North Health Network in 2016. A total of $304 \mathrm{HD}$ patients were included in this study using the census sampling method. Data were collected using a checklist, and the HBsAb level was evaluated by the ELISA test. The collected data were analyzed using analytical tests, including a chi-square test and the independent t-test.

Results: The mean \pm sd values of the serum level of HBsAb were $90.44 \pm 97.51$ and $105.73 \pm 100 \mathrm{IU} / \mathrm{L}$ in men and women, respectively. There was no association between the rate of the response to the HB vaccine and gender $(P=0.82)$, age $(P=0.13)$, weight $(P=0.09)$, vaccine injection frequency $(P=0.45)$, number of dialysis sessions/week $(P=0.36)$, and blood type $(P=0.97)$. In addition, there was no association between the response to the $\mathrm{HB}$ vaccine and the history of T2DM, HTN, renal transplantation, and cigarette smoking among the participants $(P>0.05)$.

Conclusion: One could conclude that the dialysis duration and the last injection of the $\mathrm{HB}$ vaccine would have a negative effect on the immune response rate among HD patients.
\end{abstract}

Keywords: Hepatitis B Virus, Vaccination, Hemodialysis, Seroconversion

\section{Introduction}

The hepatitis $B(\mathrm{HB})$ virus is a global public health problem that is considered a major cause of cirrhosis and liver cancer [1]. A total of 240 million people have a chronic HB infection worldwide, which results in approximately 780,000 deaths per year from the HB infection, 650,000 deaths from cirrhosis and liver cancer due to the chronic $\mathrm{HB}$ infection, and another 130,000 deaths from an acute HB infection. The prevalence of $\mathrm{HB}$ varies across the world. In East Asia and in the Middle East, the estimated $5-10 \%$ and $2-5 \%$ of the general population are chronically infected with $\mathrm{HB}$, respectively [2]. The prevalence of the hepatitis B virus (HBV) is moderate in Iran [3], which has been $3 \%(95 \% \mathrm{Cl}: 0.87-8.86)$ among the general population in the past 25 years [4]. Research shows that the prevalence of HB has 
decreased due to the routine vaccination of newborns against HBV since 1992 [5].

Hemodialysis (HD) patients are at an increased risk of acquiring HBV. Despite the completion of their vaccination schedule, they have lower seroconversion rates, lower protective antibody levels, and shorter seroprotection durations [6-8]. While the rate of the response to the $\mathrm{HB}$ vaccine is $90 \%$ among healthy people, it is $50-70 \%$ among HD patients [1, 9]. The reasons for high susceptibility to HBV among HD patients include invasive medical HD procedures, increased exposure to blood product transfusions, shared machines and equipment, and high prevalence of HBV among HD patients [7, 10]. Prominent fibrosis, silent clinical presentations, and atypical serologic evolution are prevalent among dialysistreated HB patients [11]. A comprehensive systematic review of the HBV infection in Iranian HD patients showed that the HBV rate varied from 0 to $9.75 \%$ among these patients across different provinces [12].

Various strategies have been employed to improve the rates of the response to the HB vaccine in HD patients, including doubling the vaccine dose (40 $\mu \mathrm{g} / \mathrm{dose})$, doing annual serological control tests, and administering a new booster dose in patients with antibody titers less than $10 \mathrm{mlU} / \mathrm{mL}[3,7,13]$. In such cases, the rate of the response to HBV could improve by up to $80 \%$ in HD patients [14]. Identifying the factors affecting the effectiveness of vaccination against $\mathrm{HBV}$ is crucial in reducing the prevalence of this disease among HD patients. Therefore, this study aims to determine the immune response of $\mathrm{HB}$ vaccination in hemodialysis patients referring to dialysis centers in the Tehran North Health Network in 2016.

\section{Materials and Methods}

This descriptive study was conducted on all HD patients who referred to dialysis centers in the Tehran North Health Network in 2016. These centers included Imam Hossein Hospital, Shahid Labbafinejad Medical Center, Hashemi Nejad Kidney Hospital, as well as Partian and Daroshafa Clinics.

In this study, due to the availability of all HD patient profiles and their limited number, the census sampling method was used, with a total of $304 \mathrm{HD}$ patients included. The inclusion criteria of the study were being negative $\mathrm{HBsAg}$ and $\mathrm{HBcAb}$, being given three dose series at a 0-, 1-, and 6month interval at least one month after the last injection. Patients who underwent renal transplantation during the study and no longer referred to the center for dialysis were excluded from the study.

Researchers explained the goals of the study to the participants and obtained verbal informed consent from eligible ones. Data were collected using a pre-desinged checklist that included data about age, gender, weight, blood type, frequency of vaccine injections, duration of vaccination completion, cigarette smoking status, history of hypertension (HTN), type 2 diabetes mellitus (T2DM), renal transplantation, number of dialysis per week, and dialysis duration. Next, the HbsAb level was measured using an ELISA test. In this study, patients with an anti-HBs titer above 10 $\mathrm{mlU} / \mathrm{mL}$ were considered protected, and an inadequate response was defined as anti-HBs $<10$ $\mathrm{IU} / \mathrm{mL}$.

Statistical analysis was performed using descriptive methods and analytical tests, including the independent samples t-test using SPSS Statistics V21.0. The significance level was set at $p<0.05$, and the confidence interval was $95 \%$.

The study protocol conformed with the ethical guidelines of the Declaration of Helsinki 1975.

In this study, we considered the HD patients' consent, personal data confidentiality, and free measurements as the principles of medical ethics.

\section{Results}

A total of $304 \mathrm{HD}$ patients, including 211 (69.41\%) men and 93 (30.59\%) women were included in this study. The mean \pm sd of the age of the participants was $57.14 \pm 17.21$ and $52.23 \pm 16.58$ in men and women, respectively. In addition, the mean \pm sd of the weight of the patients was $70.74 \pm 14.93$ and $67.17 \pm 18.30 \mathrm{~kg}$ in men and women, respectively. The mean $\pm s d$ of the number of vaccine injection was $3.57 \pm 1.33$ and $3.43 \pm 0.92$ in men and women, respectively. Besides, the mean \pm sd of the vaccination completion duration was $28.53 \pm 21.44$ months in the study population.

In terms of the dialysis procedure, the mean \pm sd of the dialysis frequency in a week was $3.67 \pm 0.31$ and $3.59 \pm 0.26$ in men and women, respectively. In addition, the mean \pm sd of the dialysis duration was $40.67 \pm 58.45$ months, i.e. $37.46 \pm 53.89$ months in men and $48.15 \pm 67.37$ months for women. In this study, $56(18.42 \%)$ men and 17 (5.59\%) women had a history of renal transplantation. A total of 85 (27.96\%) men and 52 (17.11\%) women had a history of T2DM. Similarly, the history of HTN was observed in $128(42.10 \%)$ men and $49(16.12 \%)$ women, respectively. In addition, $50(16.45 \%)$ men and $4(1.32 \%)$ women were cigarette smokers. 
In this study, serological HB status was negative in all participants before the first dialysis. The mean \pm sd of the serum level of $\mathrm{HBsAb}$ was 95.2 \pm 98.3 (IU: $90.44 \pm 97.51$ ) and $105.73 \pm 100 \mathrm{IU}$ in men and women, respectively. In addition, the mean \pm sd of the anti-HBs titer was far higher than the antibody titers considered protective.

According to the data analysis results, there was no relationship between the rate of the response to the $\mathrm{HB}$ vaccine and gender in the HD patients $(P=0.82)$. The results of the independent $t$-test showed no relationship between the rate of the response to the $H B$ vaccine and age $(P=0.13)$, weight $(P=0.09)$, vaccine injection frequency $(P=0.45)$, as well as the dialysis number per week $(P=0.36)$. In addition, no relationship was found between the rate of the response to the $\mathrm{HB}$ vaccine and blood type $(\mathrm{P}=0.97)$.

However, there was a significant association between the rate of the response to the $\mathrm{HB}$ vaccine and the last injection duration of the $\mathrm{HB}$ vaccine $(P<0.001)$ as well as between the rate of the response to the $\mathrm{HB}$ vaccine and the dialysis duration $(P=0.03)$ (Table 1).

Table 1. The status of the response to the hepatitis B virus by hemodialysis patients $(n=304)$ at the Tehran North Health Network in 2016

\begin{tabular}{|c|c|c|c|}
\hline 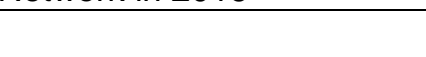 & Response to HBV & Mean \pm SD & P-value \\
\hline \multirow{2}{*}{ Age (Year) } & Negative & $59.67 \pm 18.52$ & \multirow{2}{*}{0.15} \\
\hline & Positive & $51.38 \pm 17.85$ & \\
\hline \multirow{2}{*}{ Weight (Kg) } & Negative & $70.87 \pm 13.61$ & \multirow{2}{*}{0.09} \\
\hline & Positive & $68.51 \pm 16.60$ & \\
\hline \multirow{2}{*}{$\begin{array}{l}\text { Frequency of vaccine } \\
\text { injections (Number) }\end{array}$} & Negative & $3.67 \pm 1.34$ & \multirow{2}{*}{0.44} \\
\hline & Positive & $3.55 \pm 0.76$ & \\
\hline \multirow{2}{*}{$\begin{array}{l}\text { Duration of vaccination } \\
\text { completion (Month) }\end{array}$} & Negative & $44.11 \pm 22.84$ & \multirow{2}{*}{$<0.001$} \\
\hline & Positive & $21.57 \pm 19.33$ & \\
\hline \multirow{2}{*}{$\begin{array}{c}\text { Dialysis number (Per } \\
\text { Week) }\end{array}$} & Negative & $3.04 \pm 0.27$ & \multirow{2}{*}{0.32} \\
\hline & Positive & $3.63 \pm 0.31$ & \\
\hline \multirow{2}{*}{ Dialysis duration (Month) } & Negative & $25.60 \pm 6.53$ & \multirow{2}{*}{0.03} \\
\hline & Positive & $51.27 \pm 11.65$ & \\
\hline
\end{tabular}

Independent samples t-test; at a 5\% level;

As Table 2 shows, there was no association between the response to the $\mathrm{HB}$ vaccine and T2DM, HTN, renal transplantation, as well as cigarette smoking status among participants ( $P=0.8, P=0.2, P=0.8$, and $P=0.2$, respectively).

Table 2. The relationship between the rate of the response to the hepatitis $B$ virus and the history of renal transplantation, type 2 diabetes mellitus, smoking, as well as history of hypertension among hemodialysis patients $(n=304)$ at Tehran North Health Network in 2016

\begin{tabular}{|c|c|c|c|c|}
\hline & & \multicolumn{2}{|c|}{ Response to hepatitis B virus } & \multirow[b]{2}{*}{ P-value } \\
\hline & & $\begin{array}{c}\text { Negative } \\
n(\%)\end{array}$ & $\begin{array}{c}\text { Positive } \\
\text { n (\%) }\end{array}$ & \\
\hline $\begin{array}{c}\text { Renal } \\
\text { transplantation }\end{array}$ & $\begin{array}{l}\text { Yes } \\
\text { No }\end{array}$ & $\begin{array}{l}21(6.91) \\
43(14.14)\end{array}$ & $\begin{array}{l}\frac{66(21.71)}{174(57.24)}\end{array}$ & 0.83 \\
\hline $\begin{array}{c}\text { Type } 2 \text { diabetes } \\
\text { mellitus } \\
\end{array}$ & $\begin{array}{l}\text { Yes } \\
\text { No } \\
\end{array}$ & $\begin{array}{c}26(8.55) \\
40(13.16) \\
\end{array}$ & $\begin{array}{l}90(29.60) \\
148(48.69) \\
\end{array}$ & 0.87 \\
\hline Cigarette smoking & $\begin{array}{l}\text { Yes } \\
\text { No } \\
\end{array}$ & $\begin{array}{c}25(8.22) \\
46(15.13) \\
\end{array}$ & $\begin{array}{l}47(15.46) \\
186(61.18) \\
\end{array}$ & 0.21 \\
\hline $\begin{array}{c}\text { History of } \\
\text { hypertension }\end{array}$ & $\begin{array}{r}\text { Yes } \\
\text { No }\end{array}$ & $\begin{array}{l}40(13.16) \\
31(10.20)\end{array}$ & $\begin{array}{l}131(43.09) \\
102(33.55)\end{array}$ & 0.25 \\
\hline
\end{tabular}

Independent t-test; at a 5\% level;

\section{Discussion}

There was no association between gender and the rate of the response to the $\mathrm{HB}$ vaccine. Different results have been reported for the relationship between these two variables in various studies, with positive correlations reported in some studies $[9,15-17]$ and negative correlations in some others $[1,3]$. These differences could be explained by intrinsic differences between men and women in their ability to respond to superficial hepatitis antigens. In this study, there were no differences in the rate of the response to the HB vaccine in terms of the participants' age, while most studies report an association between older ages and an impaired immune response to the $\mathrm{HB}$ vaccine $[13$, $15,18-20]$. In some other reviews, similar to the present one, no relationship of this type has been reported $[1,3]$. The reduction in the response to vaccination in older ages could stem from a change in the immune system in older ages due to 
thymus problems and decreased $\mathrm{T}$ cell functionality [21].

The results of this study showed no association between the rate of the response to the $\mathrm{HB}$ vaccine and T2DM, HTN, as well as renal transplantation among participants. There are controversial findings in similar studies about the relationship between these variables, especially between T2DM and the response to the HB vaccine $[1,13,16,17]$. There are some hypotheses about the impaired response to the HB vaccine in diabetic persons, which include a reduction in the number of circulating helper $T$ cells, the CD4-to-CD8 lymphocyte ratio, lymphocyte blastogenesis, and the presence of DR3, DR7, and DQ2 human leukocyte antigen alleles in diabetic people [22].

In this study, cigarette smoking was not shown to be associated with HBV immunization. This finding was consistent with the results of similar past studies that reported no relationship between tobacco smoking and the response to the $\mathrm{HB}$ vaccine in $H D$ patients $[13,23,24]$. However, another research showed contradictory results [25]. Regarding the high percentage of nonresponse cases in hemodialysis patients, especially in the elderly, the obese, and smokers, more attention should be paid to screening these groups of people for the anti-HBs antibody after vaccination.

Another finding of this study was that the duration of dialysis was associated with the seroconversion rate because the level of the immune response to the $\mathrm{HB}$ vaccine was lower in patients with prolonged HD. Some studies show a negative association between the duration of dialysis and the seroconversion rate $[5,13,16]$. According to another finding of the present study, a reduction in the rate of the immune response to HBV was associated with an increase in the duration of the last injection of the HB vaccine in HD patients. In general, the immune response to the $\mathrm{HB}$ vaccine decreased over time. Nevertheless, there has been a higher decrease in the mean of the serum level of HBsAb in HD patients than in the general population, and this reduction has increased more in HD patients [8, 13, 19]. In this study, like similar ones, the number of dialysis per week was not associated with the rate of the response to HBV [3]. Although some studies have reported that body mass is a determinant of the response to the HB vaccine [15], the results of the present study showed no relationship between these variables. In addition, there was no relationship between the response to the hepatitis $B$ vaccine in hemodialysis patients and the length of time during which the patient was dialyzed. In hemodialysis patients, humoral and cellular immunity is altered due to impaired phagocytosis as well as $T$ and $B$ lymphocyte functions. The number of memory $B$ cells in patients with renal failure is remarkably low, which results in lower immunoglobulin levels. As a result, the response to the hepatitis $B$ vaccine is lower in these patients [26].

It is worth noting that the major limitations of the present study were the lack of collaboration among health centers in terms of obtaining information as well as the large number of incomplete patient records.

According to the findings of this study, given that some participants were not suitable for antibody titers, booster dose injections were administered to these subjects. In addition, the time elapsed from vaccination was effective in antibody titers, and antibody titers could be periodically controlled to inject booster doses before reducing them.

\section{Conclusion}

The results from the present study showed that the durations of vaccination completion and dialysis were associated with the rate of the response to the $\mathrm{HB}$ vaccine in $\mathrm{HD}$ patients. It seems that annual serological control tests should be performed in HD patients. In addition, a booster dose of HBV vaccination is recommended for patients with antibody titers less than $10 \mathrm{mlU} / \mathrm{mL}$, who are considered non-immune patients.

\section{Acknowledgement}

The authors of the present research would like to extend their sincere gratitude to the staff of the Tehran North Health Network, which includes Imam Hossein Hospital, Shahid Labbafinejad Medical Center, Hashemi Nejad Kidney Hospital, as well as Partian and Daroshafa Clinics, who volunteered to participate in this study. This study was the abstract of an MPH student's thesis.

\section{Conflict of interest: None declared.}

\section{References}

1. Farag SE, Ghonemy TA, Soliman1 SA, Bihery A. Evaluation of hepatitis $B$ vaccine responsiveness in hemodialysis and peritoneal dialysis patients. International Journal of Research in Medical Sciences 2015; 3(9):225963.

2. World Health Organization. Hepatitis B: Fact sheet. Geneva, Switzerland: World Health Organization; 2020 July. Available from:https://www.who.int/news-room/factsheets/detail/hepatitis-b

3. Shamshirian A, Alikhani S, Alipoor R, Jafarpour $\mathrm{H}$, Espahbodi F, Azizi S. Evaluation of 
immunogenicity of hepatitis $B$ vaccine in hemodialysis patients at Mazandaran Heart Center, Iran. Biomedical \& Pharmacology Journal 2017; 10(2):557-62.

4. Mohammadi Z, Keshtkar A, Eghtesad S, Jeddian A, Pourfatholah AA, Maghsudlu M, et al. Epidemiological Profie of Hepatitis B Virus Infection in Iran in the Past 25 years; a Systematic Review and Meta-analysis of General Population Studies. Middle East J Dig Dis 2016; 8(1):5-18.

5. Ghadiani MH, Besharati Sh, Mousavinasab N, Jalalzadeh $\mathrm{M}$. Response rates to $\mathrm{HB}$ vaccine in CKD stages 3-4 and hemodialysis patients. J Res Med Sci 2012; 17(6):527-33.

6. Kong NCT, Beran J, Kee SA, Miguel JL, Sánchez C, Bayas JM, et al. A new adjuvant improves the immune response to hepatitis $B$ vaccine in hemodialysis patients. Kidney Int 2008; 73(7):856-62.

7. Barraclough KA, Playford EG. Hepatitis B virus infection in hemodialysis populations: progress toward prevention. Kidney Int 2010; 77(3):17780.

8. Jodłowska-Siewert E, Jagodziński PP, Grzegorzewska AE. Titers of antibodies tothe surface antigen of hepatitis B virus after vaccination in relation toimmunity-related gene variants. A prospective study among hemodialysis patients. Pol Arch Intern Med 2017; 127(7-8):481-9.

9. Kara $\mathrm{IH}$, Yilmaz ME, Suner A, Kadiroglu AK, Isikoglu $B$. The evaluation of immune responses that occur after HBV infection and HBV vaccination inhemodialysis patients. Vaccine 2004; 22(29-30):3963-7.

10. Cordeiro VM, Martins BCT, Teles SA, Martins RMB, Cruvinel KPS, Matos MAD, et al. Decline in hepatitis $B$ and $C$ prevalence among hemodialysis patients in Tocantins, Northern Brazil. Rev Inst Med Trop Sao Paulo 2018; 60:e36.

11. Guimarães MNC, Facincani T, Santos SSD. Hepatitis B status in hemodialysispatients. Arq Gastroenterol 2017; 54(4):356-8.

12. Djalalinia Sh, Ramezan Ghorbani N, Tajbakhsh R, Modirian M, Esmaeili Abdar Z, Mahdavi Gorabi A, et al. Hepatitis B Virus Infection in Iranian Hemodialysis Patients: a Systematic Review and Meta-Analysis. Iran J Kidney Dis 2018; 12(1):1-9.

13. Ayub MA, Bacci MR, Fonseca FLA, Chehter EZ. Hemodialysis and hepatitis $B$ vaccination: a challenge to physicians. Int J Gen Med 2014; 7:109-14.
14. Malaki M. Factors affecting on hepatitis B seroprotection in hemodialysis patients. Saudi J Kidney Dis Transpl 2017; 28(3):672-4.

15. Gasim GI, Bella A, Adam I. Immune response to hepatitis B vaccine among patients on hemodialysis. World J Hepatol 2015; 7(2):2705.

16. Sit D, Esen B, Atay AE, Kayabaşı H. Is hemodialysis a reason for unresponsiveness to hepatitis B vaccine? Hepatitis B virus and dialysis therapy. World J Hepatol. 2015; 7(5):761-8.

17. Almueilo SH. Evaluation of Response to Hepatitis B Vaccination in Chronic Hemodialysis Patients. Saudi J Med Med Sci 2017; 5(3):21823.

18. Eleftheriadis $T$, Pissas $G$, Antoniadi G, Liakopoulos V, Stefanidis I. Factors affecting effectiveness of vaccination against hepatitis B virus in hemodialysis patients. World $\mathrm{J}$ Gastroenterol 2014; 20(34):12018-25.

19. Mohammed HI, El-Hefenawy SM, Mohamed SF. Assessment of immune response to hepatitis $B$ virus vaccine in chronic hemodialysis patients. Menoufia Medical Journal 2017; 30(1):184-9.

20. Pereira ZTV, Mendoza-Sassi RA. Factors associated with the immune response to hepatitis B vaccine in Brazilian hemodialysis patients. Rev Med Chil 2012; 140(7):882-8.

21. Ponappan S, Ponappan U. Aging and immune function: molecular mechanism to intervention. Antioxid Redox Singal 2011; 14(8):1551-85.

22. Schillie SF, Spradling PR, Murphy TV. Immune response of hepatitis $B$ vaccine among persons with diabetes: a systematic review of the literature. Diabetes Care 2012; 35(12):2690-7.

23. Bonanni P, Bonaccorsi G. Vaccination gainst hepatitis $B$ in health care workers. Vaccine 2001; 19(17-19):2389-94.

24. F, Mahoney F, Coleman P, Schatz G, Hurwitz $\mathrm{E}$, Margolis $\mathrm{H}$. Immunogenicity of hepatitis B Vaccines.Implications for persons at occupational risk of hepatitis $B$ virus infection. Am J Prev Med 1998; 15(1):1-8.

25. Barash C, Conn MI, DiMarino Jr AJ, Marzano J, Allen ML. Serologic hepatitis B immunity in vaccinated health care workers. Arch Intern Med 1999; 159(13):1481-3.

26. Cordova E, Miglia I, Festuccia F, Sarlo MG, Scornavacca G, Punzo G, et al. Hepatitis B vaccination in haemodialysis patients: an underestimated problem. Factors influencing immune responses in ten years of observation in an Italian haemodialysis centre and literature review. Ann Ig 2017; 29(1):27-37. 